\title{
Translating Genetics Leaflets Into Languages Other Than English: Lessons From an Assessment of Urdu Materials
}

\author{
Alison Shaw ${ }^{1,2,4}$ and Mushtaq Ahmed ${ }^{3}$
}

Genetic counselors frequently counsel clients whose first language is not English, relying on interpreters and on supplementary translated written material. This paper highlights factors that counselors need to consider before using or commissioning translated leaflets. It is based on an assessment of leaflets translated into Urdu, the national language of Pakistan, which are available through U.K. genetics clinics for use with Pakistani-origin clients. The 2 authors, who know Urdu as their 2 nd and 1st languages respectively, independently read each leaflet, checking for accuracy of information, ease of reading and understanding, cultural sensitivity, and contact details for Urdu-speaking professionals. There were factual errors and confusing or very difficult text in all leaflets; some leaflets also contained culturally insensitive messages that could alienate users of genetics services. The paper discusses the reasons for these pitfalls and makes recommendations to guide the future production of translated genetics leaflets.

KEY WORDS: translated leaflets; genetic information leaflets; Urdu; minority languages; genetic risk; consanguinity; recessive inheritance; back-translation; cross-cultural communication; genetic counseling.

\footnotetext{
${ }^{1}$ Department of Human Sciences, Brunel University, Uxbridge UB8 3PH, United Kingdom.

${ }^{2}$ Oxford Radcliffe Hospitals N.H.S Trust, Department of Clinical Genetics, The Churchill Hospital, Oxford, United Kingdom.

${ }^{3}$ Yorkshire Regional Genetics Service Department of Clinical Genetics, Ashley Wing, St. James's University Hospital, Beckett Street, Leeds, United Kingdom.

${ }^{4}$ Correspondence should be directed to Dr Alison Shaw, Oxford Radcliffe Hospitals N.H.S Trust, Department of Clinical Genetics, The Churchill Hospital, Oxford OX3 7LJ, United Kingdom; e-mail: alison.shaw@brunel.ac.uk.
} 


\section{INTRODUCTION}

Genetic counselors frequently counsel clients whose first language is not the language of the dominant health care system. They may need to arrange for interpreters to provide verbal translation, and they may offer translated written materials as supplements to the clinical consultation. The use of interpreters and provision of translated written materials is essential if patients who are not fluent in the dominant language to have equal access to medical services and to understand fully the treatment they may be offered (Poss et al., 1993; Roberts, 2001; Schaafsma et al., 2003).

An understanding of differences in ideas about kinship and inheritance, illness causality, and attitudes to prenatal diagnosis is recognized to be important for equitable and effective "cross-cultural communication" in the delivery of genetics services to multiethnic populations (Clarke and Parsons, 1997; Penchaszadeh, 2001; Shaw, 2003a; Weil, 2001). By comparison, there has been little discussion and assessment of current interpreting and translating provision in clinical genetics. Yet individuals, couples, and families who do not speak the dominant language may be making important marital and reproductive decisions on the information they receive during genetics consultations.

Assessment of the need for interpreting and translating services, and of the type of service required-verbal translation or advocacy, translated written materials, materials in audio-visual format, and so forth-poses challenges because of the range of spoken proficiency and literacy in both dominant and minority languages within any minority population (Jones and Gill, 1998). The need for interpreters may be more than a matter of evident difficulty with the dominant language, because clients with relatively good knowledge of English may sometimes prefer to discuss difficult or sensitive material in their mother tongue. In a recent U.K. pilot study, $24 \%$ of clients from ethnic minority backgrounds indicated that English was not their preferred language for a genetics consultation (Mehta, 2003). This finding suggests that one quarter of people from ethnic minority populations seen in genetics clinics in Britain may be in need of interpreting services. This observation may also reflect a broad discrepancy between need and use of interpreting services in medicine generally in United Kingdom and in the United States (Baker et al., 1996; Woloshin et al., 1995).

Existing provisions for verbal translation in clinical genetics raise general concerns shared with other areas of medicine. Clinicians may be reluctant to use professional interpreters, relying instead on their own limited relevant language skills and assistance from colleagues, or avoiding communication with clients (Burbano O'Leary et al., 2003). Clients often prefer that a friend or relative who they know and trust acts as an interpreter, rather than as a professional (Parnes and Westfall, 2003; Xuo and Fagan, 1999). Clinicians report concerns that untrained interpreters such as the patients' relatives or friends may not translate sensitive or technical information appropriately, accurately, or at all, and their use may raise 
issues of confidentiality (Flores et al., 2003; Phelan and Parkman, 1995; Shaw, 2003a). Using trained medical interpreters does not necessarily eliminate miscommunication (Brafman, 1995; Kaufert and Putsch, 1997; Phelan and Parkman, 1995; Schaafsma et al., 2002) and may cause anxiety to the patient, especially where the interpreter's role has been inadequately negotiated beforehand (Parnes and Westfall, 2003).

Written materials can be useful in summarizing, reinforcing, or supplementing points made in a clinical consultation and in improving knowledge (Fitzmaurice, 2001; Hallowell and Murton, 1998; Little et al., 1998) especially if written in a clear and jargon-free style. The effectiveness of translated materials is partly a function of the literacy of the target population (Schaafsma et al., 2003). Written material may also be profoundly influenced by how the translation is produced, including the clarity of the original texts (Bhatt and Trevett, 1997; Buckinghamshire Health Authority, 1996; National Information Forum, 1998).

A major challenge in translation is how to convey concepts that do not have direct equivalence in another language; this is true of some apparently straightforward everyday words as well as of obviously technical terms. Kinship terms such as "cousin," "aunt," or "uncle" do not necessarily have direct translations in other languages, and apparently equivalent terms may denote a wider or a narrower category of kin than in the dominant language. In medical contexts, specialist words and phrases pose particular problems. In clinical genetics, terms such as "gene," "chromosome," and "recessive inheritance" have technical meanings that may be unfamiliar or unknown to nonspecialists, and frequently lacks direct equivalents in community languages. In these cases, translators must choose between several options. They may opt for a direct translation if the word or phrase can be found in a specialist dictionary even if it is rarely used in everyday speech; alternatively, if a general dictionary gives several alternative words or phrases they might select one of these. If the word cannot be found in a dictionary, the translator might choose an approximate equivalent in the target language or coin a new term or phrase or else leave the term untranslated. The decisions that translators make in these cases can significantly shape the meaning of the resulting text (Birbili, 2000; Sechrest et al., 1972; Temple, 1997; Twinn, 1997).

A second issue concerns the grammatical style of the translation. The grammatical structures of languages differ widely, with sometimes critical implications for meanings in translation (Sechrest et al., 1972). A literal, word-for-word translation may be technically accurate but sound stilted. The issue here is how far a translator should or can depart from the original text to produce a natural and idiomatic translation while retaining an equivalent meaning.

A third, related issue concerns the accessibility of the translation to readers from the target population. Translators are often "chosen from a population of highly educated persons who speak and write somewhat pedantically in both their languages," even though academic or "dictionary language is often not the language of the people" (Sechrest et al., 1972). A translation, although accurate, may not be 
easy to understand. Sometimes "English may at times need to be translated into English, and Urdu into Urdu" (Sechrest et al., 1972), but translators may feel that they lack the right to alter unnecessarily long and complicated English sentences.

The utility of translated material is also influenced by its presentation, readability, and ability to facilitate access to relevant health professionals. Welltranslated material in South Asian or Chinese scripts may be confusing and difficult to read if presented in a font size and design layout used for English text (National Information Forum, 1998). Information leaflets that reassure readers, at the outset, that they will be able to talk to staff in their own languages may be more likely to facilitate access to relevant services than those which do not (National Information Forum, 1998).

Finally, the translation of medical and genetic information may include material regarded as shameful or offensive in particular cultural contexts. Information concerning population-specific differences in genetic risk may also be sensitive within particular minority populations, even though such differences represent only a small fraction of overall genetic variation. For example, increased risks for autosomal recessive conditions in populations in which consanguineous and especially first-cousin marriage is an accepted and preferred practice (Bittles, 1998, and www.consang.net) may be a sensitive issue because of the importance of consanguineous marriage in many such populations, or because of the potential stigma of singling out a minority population on the basis of its marriage pattern. Culturally sensitive issues raise difficult questions for translators and commissioners of translations about the extent to which information can or should be modified to ensure cultural acceptability.

The purpose of this study was to evaluate the accuracy and cultural sensitivity of materials that have already been translated into Urdu, the national language of Pakistan, for use with British Pakistani clients. We wished to find out whether medical genetic terms that do not have direct equivalents in Urdu are translated in these materials, and if so, how. We also wished to assess the ease with which the written materials can be read and understood and whether they are likely to facilitate clients' access to relevant health professionals. Regarding cultural sensitivity, one of the issues specifically assessed in this study was how consanguinity is presented in the written materials, especially in materials about autosomal recessive disorders.

\section{BACKGROUND TO THE ASSESSMENT OF URDU LEAFLETS}

In United Kingdom, particular regional genetics centers, health authorities, health education units, and national patient organizations and charities (such as the Thalassaemia Society U.K. and the Genetic Interest Group) have taken initiatives to address some of the problems of communicating about genetics with minority language users. Several regional centers in areas of substantial South Asian settle- 
ment employ trained bilingual genetics counselors, whereas others rely on trained and untrained interpreters and advocacy. Some regional authorities and patient support groups have commissioned translations of written materials on genetic services and genetic disorders in various minority languages. One contributor to a $£ 15$ million government-funded initiative (www.doh.gov.uk/research/documents/ gkpdocument.pdf) aims to translate information leaflets on 25-30 genetics topics into 12 minority languages and make these available as an internet-based resource (http://www.londonideas.org/internet), as part of a strategy to improve access to genetics services for people of minority ethnic communities. A recent Government White Paper includes promotion of public understanding of genetics (Department of Health, 2003).

The British Pakistani population is Britain's second-largest South Asian minority according to the categories of the 2001 Census and encompasses several generations and a range of language needs. Many of the older generation are from rural northern Panjab or Azad Kashmir, speak a regional dialect of Panjabi, Mirpuri/Pahari, or Hindku at home, and have some knowledge of Urdu from Pakistan. The second generation includes U.K.-raised adults who are fluent in spoken English and Panjabi or a regional dialect with varying levels of knowledge of Urdu, and Pakistan-raised adults fluent in spoken Panjabi and educated to a higher level in Urdu than in English.

Although Panjabi or a regional dialect is the mother tongue, Pakistanis in Britain and in Pakistan do not generally use a written form of Panjabi and expect formal written communications to be in Urdu or English. In Pakistan, Urdu is language of formal communication and the medium of instruction in most schools. It is also taught to general certificate and advanced level in some British secondary schools.

In addition to the genetic conditions that occur with approximately the same frequency as in other populations, the genetic conditions that may particularly affect British Pakistanis are thalassaemia and autosomal recessive conditions including those associated with developmental delay. Analysis of birth incidence and childhood prevalence data has linked the increased risk of autosomal recessive disorders among British Pakistanis with parental consanguinity. The background risk, to any couple, of serious congenital and genetic disorder diagnosed in infancy or childhood (approximately 3-4\%) doubles for first cousins (to approximately 6$8 \%$ ), and triples (to 9-12\%) for first cousins where there is also a history of consanguineous marriage in the family, with the excess due mainly to recessive conditions (Bundey and Alam, 1993).

The increased risk for recessive conditions associated with consanguineous marriage is a particularly sensitive issue in relation to the British Pakistani population. In Pakistani society, courtship is discouraged, parents are usually responsible for arranging their children's marriages, and marriage within the family is traditionally viewed as a means of reducing the social risks of marrying outside the family. Cousin marriages continue to be favored by many second-generation 
British Pakistanis, among whom the rate of cousin marriages may have increased in comparison with the previous generation (Darr and Modell, 1988; Shaw, 2001).

In Britain, as in the U.S.A. (Ottenheimer, 1996), cousin marriages are generally disapproved by the majority population and widely believed to carry "high" genetic risk. In United Kingdom, the genetic risks of consanguineous marriage have generated national medial attention as well as heated debates over appropriate genetic service delivery (Modell and Darr, 2002). Some health professionals and community groups advocate discouraging consanguineous marriages through community education and the dissemination of genetic epidemiological research, whereas others argue that an undue emphasis on "cousin marriages" is a form of racism and will alienate potential uses of genetics services (Ahmad, 1996).

British Pakistanis are underrepresented at genetics clinics (Roberts et al., 1996). The reasons for this may include nonreferral by clinicians who may assume that, as Muslims, Pakistani clients are not interested in using antenatal genetic screening (Modell et al., 2000; Sandall et al., 2001). There is also a lack of knowledge of genetic causes of illness and of what genetics services can offer, particularly among people with origins in rural northern Panjab and Azad Kashmir, who recognize both spiritual and environmental causes of a range of conditions that are understood in western medicine to be of genetic origin (Shaw, 2004). In addition, there is a dearth of appropriately trained bilingual interpreters and genetic professionals in U.K. genetics clinics. Cousin couples are sometimes also reluctant to use genetics services for fear that clinicians will "blame" them for the incidence of genetic disorder (Darr, 1999; Shaw, 2003b). We therefore considered it important that our study of written materials about genetics for British Pakistani readers should include an examination for possible bias regarding cousin marriages, especially in materials dealing with autosomal recessive conditions.

\section{METHODS}

We asked all of the U.K. regional genetics centers $(n=27)$ for copies of any leaflets available in Urdu. All of the centers replied to our enquiry, which produced seven leaflets and a booklet. These consisted of two leaflets about genetics services; one leaflet about recessive inheritance; one leaflet about Down's syndrome screening (maternal serum screening); three leaflets about pregnancy, cousin marriages, and genetic risk; and a booklet (in two different editions) about "being a carrier of thalassaemia." Table I gives a summary of the content, intended use, and mode of production of each item.

Both authors assessed each item. Mushtaq Ahmed is a native Urdu speaker and a trained interpreter, translator, and genetic counselor who has worked mainly with the British Pakistani community for 12 years. Alison Shaw is a native English speaker who has learnt Urdu as a second language, taught Urdu and trained Urdu teachers in adult education, and has worked for over 20 years with British 


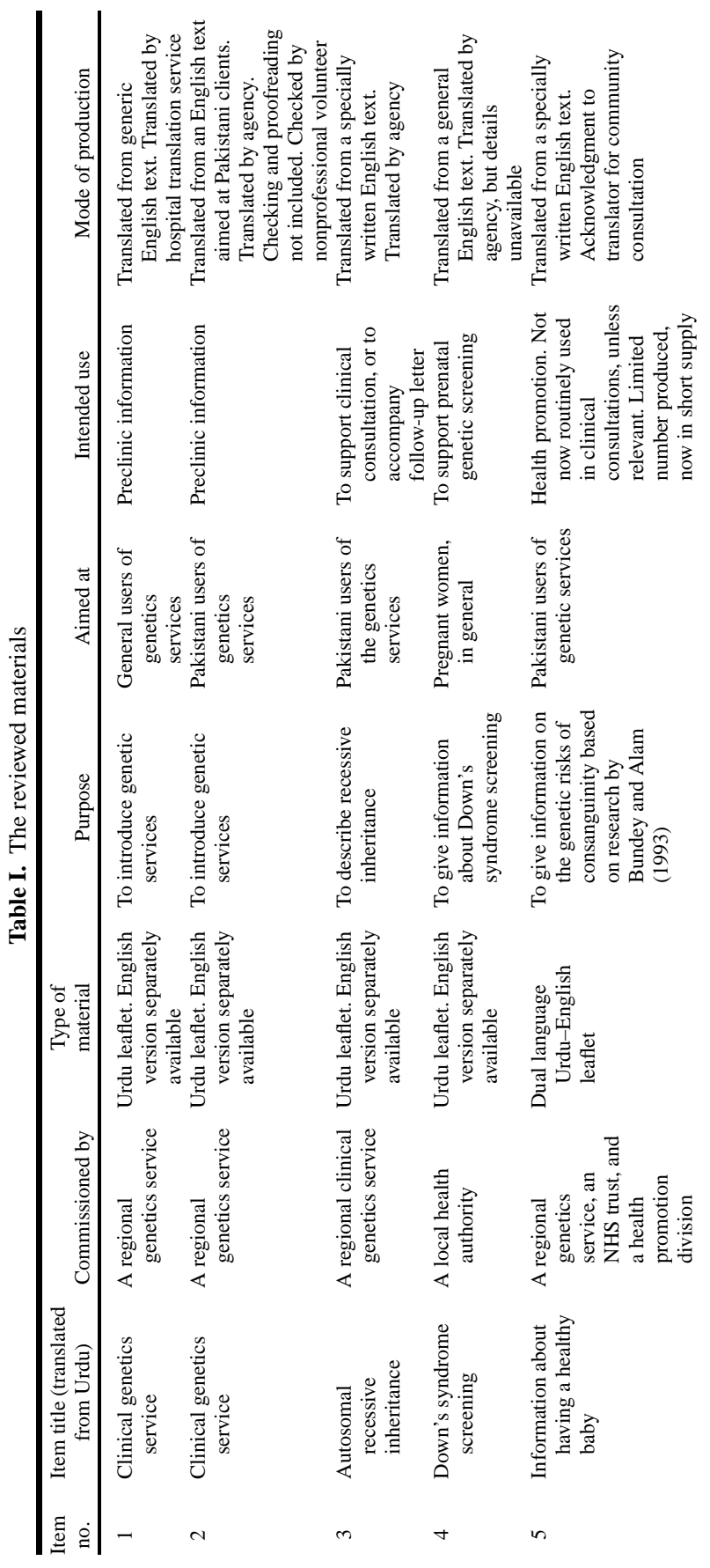




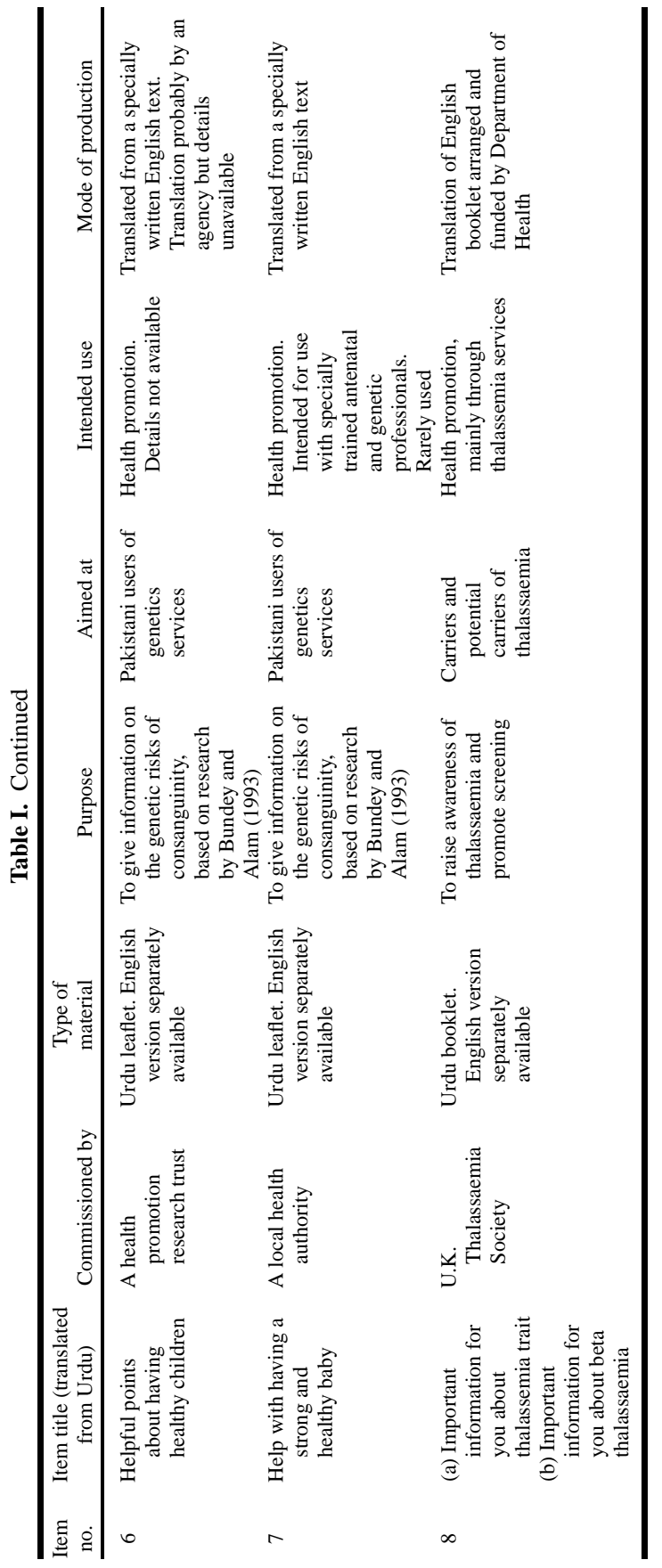


Table II. Checklist

- Are easy, everyday Urdu words and phrases used?

- Are English technical terms explained?

- Is there a corresponding English text?

- Is the print large enough to read easily?

- Is the sequence of information clear?

- Do diagrams make sense to lay readers?

- Can a health professional who does not read Urdu identify the leaflet?

- Are there contact details for relevant agencies and Urdu-speaking professionals?

Pakistani families as a social anthropologist. Her current research is on the impact of genetic risk information on British Pakistani families referred for genetic counseling (Shaw, 2003b).

The authors independently assessed each item, reading it without reference to the English version, translating it back into English to check the meaning and accuracy of information, and noting the difficulty of phrasing and vocabulary and if medical or technical concepts lacking easy Urdu equivalents are explained, and if so how. We also assessed the presentation of the items, whether diagrams made sense to readers and whether the leaflets or booklets are likely to facilitate access to health professionals. The assessment questions are listed in Table II. We also noted how the issue of genetic risk and cousin marriages is presented, particularly in the materials on autosomal recessive inheritance.

For ease of reference, we also produced an English (Roman) transliteration of the original Urdu text that can be read by Urdu speakers who do not read the Urdu script fluently. Transliteration enables the sounds of one language to be represented in approximately corresponding characters of a different script; for instance, the Urdu word for "danger" can be represented in Roman script as khatra. Roman transliteration is often used in language teaching, where the emphasis is on the spoken rather than the written form, and may be used for the training of interpreters familiar with spoken rather than written Urdu. The Roman transliterations and back-translations together with detailed comments on the choice of words and phrases and suggestions for improvement are available on request.

As an additional means of validation, the first author cross-checked her own assessment of the difficulty of particular words or phrases, which is based on her experience of knowing Urdu as a second language, against the reactions of five people from two Urdu-/Panjabi-speaking households originally from rural Jhelum and Mirpur. Among these five people, the highest formal level of knowledge of literary Urdu was FA (approximately equivalent to U.K. advanced level) from Pakistan.

\section{RESULTS}

Our results were consistent and complementary. We found recurring problems with the content, presentation, and utility of the leaflets and booklets. Table III lists 
Table III. Common Pitfalls

- Difficult technical information given in difficult language

- Incorrect, confusing, contradictory or insensitive messages

- Literal translations of English text

- Excessive or unnecessary information

- No English text

- Very small Urdu print

- No contact details of someone to talk to in Urdu or Panjabi

these common pitfalls. Regarding content, we found that all of the reviewed items contained some inaccurate, misleading, or inadequate information. They all also contained some difficult or unfamiliar words, transliterated English words, and stilted phrasing. We list these types of translation error, with examples, in Table IV.

Table IV. Types of Translation Error, With Examples

\section{Inaccurate information}

- "planning your family" becomes "family planning"

- "tests during pregnancy" become "pregnancy tests"

- "treatment" becomes "cure"

- "carrier" becomes "sufferer"

- "recessive" becomes "subdued" or "out-of-sight"

- (recessive) "factor" becomes "political agent"

- "genetic counselor" becomes "expert in procreation"

- "encourage" becomes "persuade"

- "genes" becomes "inherited cells"

- "artificial insemination" becomes "pregnancy without semen"

- "risk" becomes "danger"

- "high-risk screen" becomes "too much dangerous screen"

- "disorder" (of blood) becomes "speciality"

- "rare" becomes "precious"

- "generally" becomes "completely"

- "abnormalities" becomes "irregularities"

- "serious problem" becomes "these kinds of problem"

- "aunt/uncle" becomes "father's younger brother's wife/mother's brother's wife"

- "people who carry beta thalassemia" become "beta thalassaemia people"

- "frequent blood transfusions and other medical treatment" becomes "cures from doctors and change of blood"

Difficult or unfamiliar Urdu vocabulary

- word for "cell" (khulia)

- word for "ovum" (beze)

- phrase for "sperm" (mada-tauleed, i.e., "material of procreation")

- words/phrases for: conception, complicated, family, to offer, translator, to explain, meaning, defect, before, stage of pregnancy, visibility (of markers), infectious, level gene, cystic fibrosis, and thalassaemia

Missing text, transliterated English words

- "increase in birth defects" becomes "increase of birth"

- Transliterated words: genes, recessive genes, chromosome, control, cousin, surveillance, scanning, checkup, carriers, healthy carriers, markers, register, genetic clinic, alpha feto protein, spinabifida test, human chorionic gonadotrophin, ultrasound scan, abnormal haemoglobin, names of illnesses, and place names of genetics clinics 
Table V. Frequency of Translation Errors

\begin{tabular}{lcccccc}
\hline Item & $\begin{array}{c}\text { Inaccurate } \\
\text { information }\end{array}$ & $\begin{array}{c}\text { Difficult or } \\
\text { unfamiliar } \\
\text { Urdu vocabulary }\end{array}$ & $\begin{array}{c}\text { Transliterated English, } \\
\text { stilted phrasing/ } \\
\text { omitted text }\end{array}$ & $\begin{array}{c}\text { Total } \\
\text { errors }\end{array}$ & $\begin{array}{c}\text { Word } \\
\text { count }\end{array}$ & $\begin{array}{c}\text { Weighted } \\
\text { total errors }\end{array}$ \\
\hline 1 & 9 & 15 & 29 & 53 & 732 & 7.2 \\
2 & 4 & 4 & 2 & 10 & 372 & 2.7 \\
3 & 2 & 4 & 10 & 16 & 441 & 3.6 \\
4 & 7 & 26 & 34 & 67 & 829 & 8.1 \\
5 & 10 & 12 & 13 & 35 & 952 & 3.7 \\
6 & 7 & 24 & 12 & 43 & 1.120 & 3.8 \\
7 & 4 & 10 & 36 & 50 & 955 & 5.2 \\
8 & 75 & 54 & 69 & 198 & 3.315 & 6.0 \\
\hline
\end{tabular}

In Table V, we show the approximate frequency with which the different types of error occurred in each item. To allow for a very approximate comparison across items while taking account of the considerable variation in their lengths, we also calculated a weighted total number of errors for each item.

Some items also contained messages that were insensitive to the cultural background, particularly with respect to the issue of the genetic risks of cousin marriages, and we discuss these findings below. The items also varied in quality of presentation, and in their ability to facilitate access to health professionals varied. We list the strengths and weaknesses of presentation and utility in Table VI.

\section{DISCUSSION}

\section{Inaccurate Information}

Inaccurate, misleading, or confusing information is frequently the result of errors in the translation of specialist terms and concepts. Errors can arise through direct or literal translation, where a technical term loses its specialist meaning, where a technical distinction between English terms is not maintained in translation, and where a specialist concept is inaccurately translated.

Literal translation of technical terms was a common source of inaccurate information. In the jargon of antenatal tests, for example, the phrase "positive result" means that a fetus is affected, but in literal translation this conveys the misleading message that termination of pregnancy may be offered following a favorable result. Similarly, the phrase "high-risk screen," which is intended to refer to the testing of women at "high risk" of having an affected fetus, becomes "too much dangerous screen," implying that the test itself is extremely dangerous.

Inaccurate translation of technical terms and phrases was another common cause of error. For example, the technical English phrase "artificial insemination" is 


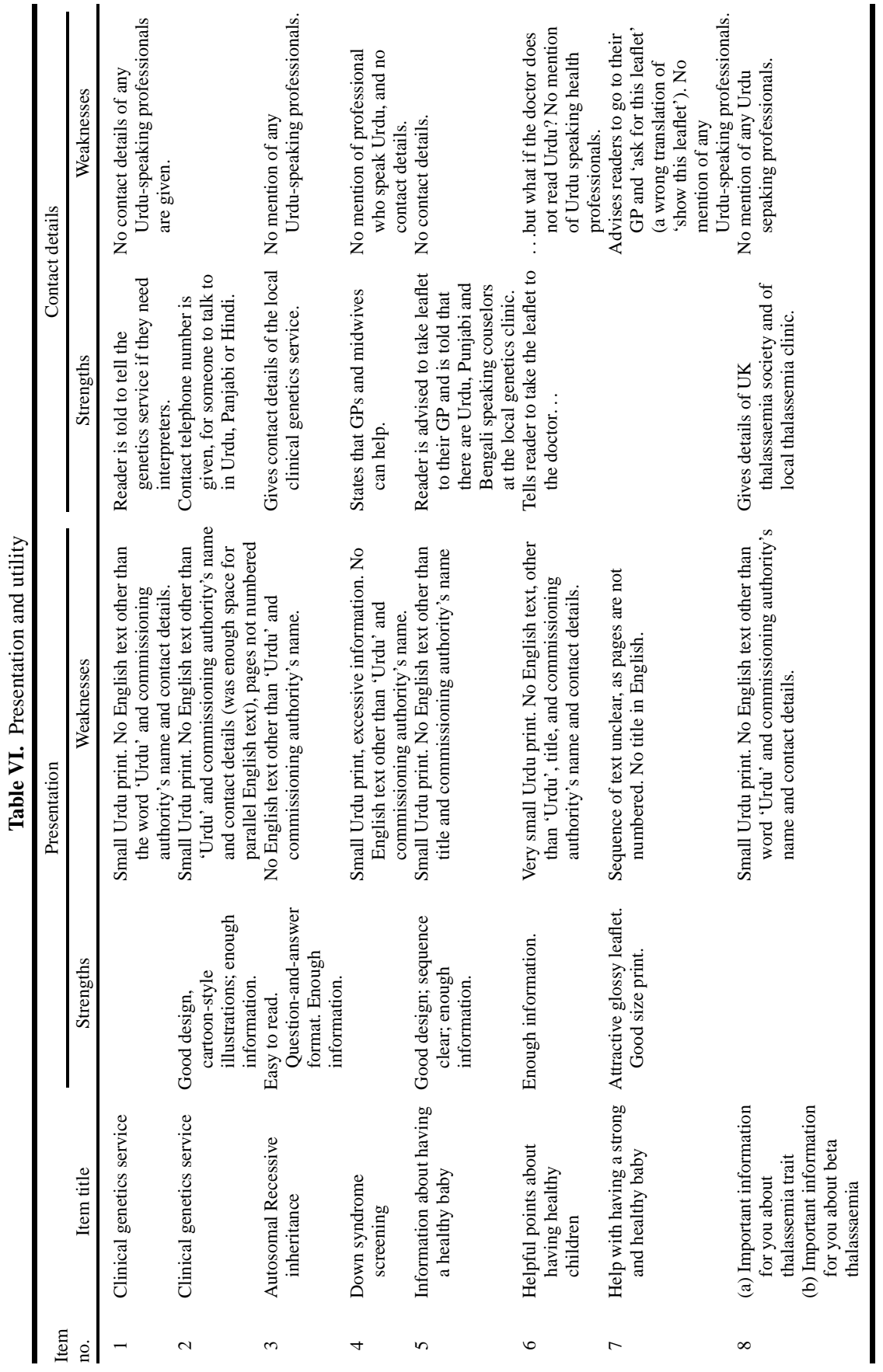


translated as "pregnancy without semen." Similarly, the English phrase "planning your family," which in the English text means "planning to have children," is translated by the Urdu phrase "family planning" which means birth control and gives the impression that having more children is being discouraged.

Confusing messages can also result if a technical distinction in the original is not maintained in translation. In both editions of the thalassaemia booklet, the verb mubtala hona (literally, "to be involved in" or "to be afflicted by" and, by extension, "to suffer") is used to describe both an unaffected carrier of thalassaemia and someone who suffers from the disorder. This failure to distinguish between "carrier" and "affected" states completely defeats the purpose of the booklets, which aim to give information about being a thalassaemia carrier. The implication that a carrier is someone who is ill might cause needless anxiety to the thalassaemia carriers for whom these booklets are intended.

Inaccurate messages can also result from inadequate explanations of technical concepts such as "gene" or "recessive inheritance," which may have been inadequately explained or may not have been explained at all in the original English text. One Urdu leaflet defines "genes" as "inherited cells" (which "control the transfer to offspring of all kinds of human specialities") in a footnote that is absent from the English version; presumably, the translator or commissioner of the translation perceived a need for an explanation in Urdu. The same point could be made of the English version.

Four leaflets and one booklet describe "recessive inheritance." However, none of these items explain clearly or convincingly the contradictory idea that someone can "carry" a genetic illness, and be at risk of having affected children, without suffering from it themselves. Moreover, as noted above, the distinction between carrier and sufferer is entirely lost in one translation.

The concept of "recessive inheritance" is difficult to convey even in English to people untrained in genetics. When asked to recall recessive risk, genetics clinic attendees usually remember the 1 in 4 chance of having an affected child but not the other possible outcomes (Snowdon and Green, 1994). They also tend to underestimate the extent to which siblings have genes in common (Richards and Ponder, 1996). The reason for this is probably their inadequate knowledge of single-gene inheritance and in particular that one copy of each gene is inherited from each parent (Richards and Ponder, 1996). If the objective is to counsel carrier couples about their own reproductive risks, this may seem a relatively unimportant observation, because the important clinical message (the 1 in 4 recurrence risk) has been grasped. However, the counseling implications are wider than this, especially for couples from families in which consanguineous marriage is practiced, because carrier couples may also need to understand that their close relatives (such as siblings or children) may also be carriers and at risk of having affected children themselves if they marry other carriers. 


\section{Unfamiliar or Difficult Urdu Words}

Literary or academic Urdu uses words that may not be used or understood in everyday language. Two leaflets contained only a few difficult Urdu words, whereas other items contained many. The Urdu word for "cell" (khulia), for instance, is unfamiliar to many speakers of everyday Urdu and does not appear in nonspecialist Urdu-English dictionaries. The Urdu word for "ovum" (beze) had neither of us heard of the Urdu word for "ovum" (benz). The very idea of female reproductive gametes may, like the concept of cell, be unfamiliar to many potential readers. Translators may feel obliged to find and use direct translations of technical terms, but readers may not know these words.

Some difficult words proved not to be Urdu but transliterated English words. These included technical genetic terms such as "recessive," "genes," and "chromosome," medical terms such as "alpha feto protein," "human chorionic gonadotrophin," the names of illnesses and the names of British towns, none of which have direct translations in Urdu. Other transliterated words, such as "baby" and "health" and "register" (as in "register your name at an antenatal clinic"), have everyday Urdu equivalents that could have been used and were used in some items but not in others. In Pakistan and in Britain, English words are often used in both spoken and written Urdu, though not always with the same meanings as in English (National Information Forum, 1998). However, there was little consistency across the items in which words were transliterated. Transliteration was sometimes chosen because translation could not be achieved with one word. (An idiomatic translation of "cousin," for instance, translates back as "father's brotherborn, father's sister-born, mother's brother-born, or mother's sister-born brother or sister.")

Other unusual words and phrases are the results of attempts to translate a technical word by adapting a word or phrase in the target language or coining a new term. One leaflet translates "recessive" as "subdued" (daba hua); another, drawing on literary Urdu vocabulary, translates it as "out-of-sight." In the Urdu version of a health-education video (not reviewed here) about the risks of recessive disorders, "recessive" was translated by a phrase that literally means "sitting in the corner," and might in literary circles be used of a shy and retiring child.

We found that complicated sentences that did not make sense, usually combined with difficult Urdu vocabulary and/or transliterated English words, occurred most often in the items written for a general audience. These seemed usually to be direct translations of overly academic or complex English sentences. Sometimes even short phrases such as headings and subheadings did not make grammatical sense. The problem here, as with the translation of long and complicated English sentences, may be that the translators do not feel that they have the freedom to rephrase the text in natural Urdu, but consider that they should stay close to the original English. 


\section{Presentation}

In most of the leaflets, the only English text is the name of the commissioning authority and the word "Urdu," and sometimes the language of the translation is not stated. The lack of an English text prevents health professionals who do not read Urdu from identifying potentially useful leaflets and assessing their relevance for particular clients. It also prevents Urdu readers from cross-checking the meaning of particular words or phrases and inhibits shared reading in families where confidence in reading English and Urdu varies.

One leaflet contains a parallel Urdu and English text, together with a duallanguage list of technical terms with explanations. This is particularly useful. Many young British Pakistani adults of childbearing age have spouses raised in Pakistan who read Urdu. For such families, a bilingual leaflet, in English and Urdu, would supplement discussions with clinicians, while encouraging shared reading (in Urdu or English) and facilitating discussion at home and with other family members.

\section{Accessing Professionals and Obtaining Further Information}

All of the leaflets advise readers to talk to health professionals and to seek further information. One leaflet giving introductory information about genetic services provides specific contact details for Urdu-speaking professionals. Another leaflet produced by the same genetics service states that professionals able to speak to clients in their own languages are available at the local genetics clinic.

However, none of the other leaflets provide any contact details for Urdu- or Panjabi-speaking health professionals; the reader may presume that such professionals are unavailable. One of the three leaflets on pregnancy, cousin marriages, and genetic risk advises the reader to go to their family doctor and "ask for this leaflet" (a mistranslation of "take" this leaflet), but what is their doctor supposed to do if he or she cannot read Urdu and there is no English text?

\section{Cultural Sensitivity: Recessive Risk and Consanguineous Marriage}

Three of the reviewed items were designed mainly for antenatal use and health promotion and offer Pakistani readers information about the genetic risks of consanguineous marriage (Table I). In our view, these items give the impression that cousin couples are being singled out and "blamed" for the birth of affected children. This impression is conveyed unintentionally through the sequence of information and through the way in which particular terms have been translated. 
In each item, information about the "dangers" of cousin marriages immediately follows information about "having a healthy baby." Genetic "risk" is translated as "danger," suggesting that every cousin marriage will necessarily result in the birth of children with genetic disorders, rather than this being a matter of chance or probability. The English word "cousin" is often used, merely transliterated (as "kazan") rather than the various Urdu equivalents that denote first cousins or other relatives. Many British Pakistanis know the English word "cousin" in the context of public debates over "cousin marriages." However, in the discussion of the relative genetic risks of different types of consanguineous marriages (the risks for first cousins, compared with risks for first cousins with a history of consanguineous marriage in the family, or for first cousins once removed, second cousins, etc.) imprecise translation of kinship terms makes it unclear which consanguineous unions are being singled out for discussion — even though distinguishing different degrees of relatedness is essential for estimating genetic risk (Bennett et al., 2002). Two leaflets reinforce the negative emphasis given to cousin marriages by advising cousin couples to see their doctor about "family planning" to avoid the birth of affected children.

In the absence of a convincing explanation of how recessive inheritance works that might help to clarify the link between genetic risk and cousin marriage, it may therefore seem that cousin couples are being discouraged from having children altogether. As we have already noted, in the thalassaemia booklets, couples are told that "pregnancy without semen" is a means of preventing thalassaemia. Rather than facilitating access to the relevant clinics and agencies, such implicitly eugenic messages may have the opposite effect and alienate potential users of the genetics service. British Pakistanis do sometimes avoid contact with antenatal and genetics services for fear that they will be criticized for being married to cousins or told that they should not have children (Shaw, 2003b).

\section{Counseling Implications: Recessive Risk and Consanguineous Marriage}

It is important that genetic counseling does not unwittingly reinforce the stigma associated with cousin marriage in Europe and America by exaggerating the genetic risks of such marriage. Inconsistent advice and estimates of genetic risk provided to couples in the United States (Bennett et al., 1999) justify recent recommendations for the preconception, antenatal and neonatal screening, and counseling of consanguineous couples (Bennett et al., 2002). These recommendations are that "beyond a thorough family medical history with follow-up of significant findings, no additional preconception screening is recommended..." and "consanguineous couples should be offered similar genetic screening as suggested for any couple of their ethnic group" (Bennett et al., 2002). In pregnancy, consanguineous couples, like nonconsanguineous couples, should be offered maternalfetal serum-marker screening and ultrasound scanning. They should also be offered 
both standard and supplementary screening for newborn infants because the early identification of medical problems of genetic origin (hearing impairment and inborn errors of metabolism) improves the chances of successful treatment (Bennett et al., 2002).

We consider these recommendations to be relevant for the genetic screening and counseling of consanguineous U.K. Pakistani couples. As for other South Asian groups, thalassaemia-carrier testing is indicated for all Pakistani couples. There is, in addition, the increased risk of recessive genetic disorders to offspring of cousin couples from families with a history of consanguineous marriage, where, for instance, parents and grandparents are also cousins. The genetic effect of a family history of consanguinity is an increase in rare recessives (for many of which carrier testing remains unavailable) rather than in any single condition. On the basis of current genetic knowledge, this does not appear to justify any additional preconception screening other than that indicated by the family history. There would seem, therefore, to be little clinical justification for highlighting the genetic risks of cousin marriages in written materials dealing with preconception, antenatal and neonatal screening. Even for a cousin couple with a history of consanguinity in the family, the chance of having a child unaffected by a congenital or genetic disorder is at least $88 \%$.

The recent recommendations focus on preconception, antenatal and neonatal screening for consanguineous couples (Bennett et al., 2002), rather than on the counseling implications for consanguineous couples where there is a family history of both consanguineous marriage and a family history of recessive disorder, for instance, following the diagnosis of a recessive condition in a child. We consider it particularly important for informed marital and reproductive decision making that couples in this situation receive a clear and convincing explanation of how a recessive gene may be shared by siblings, and of how someone who is a carrier risks having affected children if they marry another carrier, as discussed above. In this context, written materials explaining recessive inheritance and presented in an unbiased manner with regard to consanguineous marriages may usefully support explanations offered by clinicians during genetics consultations and facilitate discussion with other family members. This observation may also be relevant to the counseling of consanguineous couples from other ethnic backgrounds where there is both a family history of recessive disorder and a tradition of consanguineous marriage.

\section{RECOMMENDATIONS}

Many of the problems of inaccurate or confusing information and difficult or unfamiliar vocabulary can be overcome in the translation of genetics information, even when translating into a language that lacks technical genetic concepts. In the first place, careful attention needs to be given to the preparation of the English text, 
especially to the use of unfamiliar genetic jargon, which can conjure up alarming images even among speakers of the dominant language (Abramsky and Fletcher, 2002; Chapple et al., 1997). In their consultations with patients, genetics professionals speaking in English often have to explain technical concepts in everyday language: we recommend that clear, simple, and understandable language is also used in written materials.

Some technical genetics terms and concepts, such as genes, chromosomes, and recessive inheritance, are central to understanding the messages of genetics leaflets or booklets, and their use cannot be avoided even though they may lack any obvious equivalents in the target language. In this case, we think it best to retain the English word or concept rather than to attempt to coin a new word or phrase, and to offer an explanation for it in everyday language. The term can be retained by transliterating and writing in English as well (in brackets) to indicate that it is an English word. It should then be explained clearly and carefully using everyday words from the target language rather than literary or academic vocabulary. Where possible, the explanation should be given at the first occurrence of the term or concept. We recommend, in addition, a dual-language glossary of technical terms.

Ideally, translators would be minority language-speaking professionals experienced in discussing clinical genetics in everyday language with clients and familiar with the linguistic style of the target population. Such professionals may be able to prepare a text or key sections of it in the target language directly, rather than from a translation (National Information Forum, 1998), and produce an accompanying English text afterwards. Alternatively, translators should be prepared to work in close collaboration with genetics professionals, especially over the development of everyday explanations of technical terms.

Once a translation is drafted, its meaning can be checked through backtranslation into English, which should be done by a different translator. Some translation agencies provide validation through back-translation as part of their service, but often an additional fee is charged. Checking for discrepancies between the two English versions, improving the translation, and checking it through further back-translation should enable many of the errors of inaccurate translation and missing text (see Table IV) to be avoided. However, back-translation can introduce further inconsistencies and will not detect all errors of meaning. Its major advantage "is that it operates as a filter through which nonequivalent terms will not readily pass" (Sechrest et al., 1972); nonequivalent terms, central to the message of the leaflet, may need to be retained, transliterated, and explained, as discussed above. Back-translation may also reveal unanticipated problems with the English text, which can then be improved upon. We recommend that the minority language and the English version are presented in the same leaflet or booklet, as a dual-language text.

Other problems of translation such as stilted phrasing and difficult or unfamiliar vocabulary, including transliterated English words, may not be detected 
Table VII. Recommendations

- Close collaboration between bilingual professionals and translators

- Freedom to use words and phrases of target language

- Minimal use of technical terms and no unnecessary information

- Technical terms explained clearly in everyday words and phrases

- Freedom to change and improve the English text

- Appropriate print size

- Dual language text, including glossary terms and explanations

- Piloting with target population

by back-translation alone. These problems should be avoidable by using translators familiar with the linguistic style of the target population. In addition, the draft dual-language leaflets should be carefully proofread and then piloted with the target populations. Piloting through informal feedback or planned discussion groups may generate useful suggestions for improvements to the phrasing and presentation (National Information Forum, 1998).

English leaflets containing a lot of information and not written with any particular population group in mind are likely to pose particular problems for translators because levels of knowledge of genetics and issues of cultural sensitivity vary. Where a generic English leaflet is being translated into many different languages, it may be better to select only the most essential information for translation, and to rewrite this information in a style appropriate for each particular linguistic/ethnic group and produce a new parallel English text. The resulting dual-languages leaflets would then supplement the generic English leaflet.

Our recommendations (summarized in Table VII) are broadly similar to the recommended protocol for the development of translated questionnaires for use in cross-cultural contexts (Shumaker and Berzon, 1995). They also closely parallel guidelines for providing information to minority language users based on an assessment of health promotion leaflets produced in Urdu in United Kingdom which showed many leaflets were inaccurate and difficult to read (Bhatt and Trevett, 1997; Buckinghamshire Health Authority, 1996; National Information Forum, 1998). The general guidelines may be fairly well-known but are evidently not always followed. In clinical genetics, families and couples may be basing important decisions on the information they receive from clinicians, so it is essential that these mistakes are not repeated.

\section{Future Directions}

Written information can be useful in improving knowledge or in reinforcing or supplementing points made in a clinical consultation, but cannot substitute for personal communication (Fitzmaurice, 2001; Little et al., 1998). Likewise, translated leaflets should never be regarded as an alternative to personal communication between clinicians and clients. Every effort should be made to recruit graduates 
able to speak relevant minority languages into genetic counseling training programs, and to provide appropriate support for bilingual staff. Training and support might include the development of materials and forums in which interpreters, translators, and bilingual counselors share their expertise in explaining genetic concepts in minority languages.

Finally, our recommendations for translating genetics leaflets are also relevant for translating the information sheets and consent forms used for genetic research. Research ethics committees require this information to be accurate, easy to understand, and accessible. If these principles are to extend to written translations, there will need to be some form of check on the accuracy and ease of reading and understanding of translations.

\section{ACKNOWLEDGMENTS}

Alison Shaw's research is supported by the Wellcome Trust (Ref. No. 063078). We are grateful to all U.K. regional genetics centers for responding to the request for leaflets. We thank Jane Hurst, Pritti Mehta, Saghira Malik, Paramjit Gill, and Josephine Green for their comments on the first version of this paper. We thank the editor and two anonymous reviewers for the Journal of Genetic Counseling for their helpful suggestions for revision.

\section{REFERENCES}

Abramsky, L., \& Fletcher, O. (2002). Interpreting information: What is said, what is heard-A questionnaire study of health professionals and members of the public. Prenat Diagn, 13, 1188-1194.

Ahmad, W. (1996). Consanguinity and related demons: Science and racism in the debate on consanguinity and birth outcome. In C. Samson \& N. South (Eds.), The Social Construction of Social Policy: Methodologies, racism, citizenship and the environment (pp. 68-87). London: Macmillan.

Baker, D. W., Parker, R. M., Williams, M. V., Coates, W. C., \& Pitkin, K. (1996). Use and effectiveness of interpreters in an emergency department. JAMA, 275, 783-788

Bennett, R. L., Hudgkins, L., Smith, C. O., \& Motulsky, A. G. (1999). Inconsistencies in genetic counseling and screening for consanguineous couples and their offspring: The need for practice guidelines. Genet Med, 1, 286-292.

Bennett, R. L., Motulsky, A. G., Bittles, A., Hudgins, L., Uhrich, S., Doyle, D. L., et al. (2002). Genetic counseling and screening of consanguineous couples and their offspring: Recommendations of the national society of genetic counselors. J Genet Counsel, 11(2), 97-119.

Bhatt, A., \& Trevett, N. (1997). Many voices, one message: Guidance for the development and translation of health information. Health Education Authority, London.

Birbili, M. (2000). Translating from one language to another. Soc Res Update, Issue 31. Retrieved from http://www.soc.surrey.sc.uk/sru/SRU31.ht

Bittles, A. H. (1998). Empirical estimates of the global prevalence of consanguineous marriage in contemporary societies. Standford, CA: Stanford University, Morrison Institute for Population and Resources Studies.

Brafman, A. H. (1995). Beware of the distorting interpreter. BMJ, 311, 1439.

Buckinghamshire Health Authority. (1996). Communicating with our ethnic minority communities: How should we do it? A survey of good practice, practical experience and community ideas. Buckinghamshire: Author. 
Bundey, S., \& Alam, H. (1993). A five-year prospective study of the health of children in different ethnic groups, with particular reference to the effect of inbreeding. Eur J Hum Genet, 1, 206-219.

Burbano O'Leary, S. C., Federico, S., \& Hampers, L. C. (2003). The truth about language barriers: One residency program's experience. Pediatrics, 111, 569-573.

Chapple, A., Campion, P., \& May, C. (1997). Clinical terminology: Anxiety and confusion amongst families undergoing genetic counseling. Patient Educ Counsel, 32, 81-91.

Clarke, A., \& Parsons, E. (1997). Culture, kinship and genes: Towards cross-cultural genetics. London: Macmillan.

Darr, A. (1999). The patient perspective. In P. Rose \& A. Lucassen (Eds.), Practical genetics for primary care (pp. 331-338). Oxford: Oxford University Press.

Darr, A., \& Modell, B. (1988). The frequency of consanguineous marriage among British Pakistanis. J Med Genet, 25, 191-194.

Department of Health. (2003). Our inheritance, our future: Realising the potential of genetics in the N.H.S. White Paper.

Fitzmaurice, D. A. (2001). Written information for treating minor illness: Alone, it's not very valuable-But we shouldn't expect it to be. BMJ, 322, 1193-1194.

Flores, G., Laws, M. B., Mayo, S. J., Zuckerman, B., Abreu, M., Medina, L., et al. (2003). Errors in medical interpretation and their consequences. Pediatrics, 111, 6-14.

Hallowell, N., \& Murton, F. (1998). The value of written summaries of genetic consultations. Patient Educ Couns, 35, 27-34.

Jones, D., \& Gill, P. (1998). Breaking down language barriers: The NHS needs to provide accessible interpreting services for all. BMJ, 316, 1476.

Kaufert, J. M., \& Putsch, R. W. (1997, Spring). Communication through interpreters in healthcare: Ethical dilemmas arising from differences in class, culture, language and power. J Clin Ethics, $8(1), 88-93$

Little, P., Griffin, S., Kelly, J., Dickson, N., \& Sadler, C. (1998). Effect of educational leaflets and questions on knowledge of contraception in women taking the combined contraceptive pill: Randomised controlled trial. BMJ, 316, 1948-1952.

Mehta, P. (2003). Ethnic monitoring in clinical genetics: Project report. Retrieved from http://www.gig.org.uk/docs/final_report3.pdf

Modell, B., \& Darr, A. (2002). Genetic counselling and customary consanguineous marriage. Nat Rev, 3, 225-229.

Modell, B., Harris, R., Lane, B., Khan, M., Darlison, Petrou, M., et al. (2000). Informed choice in genetic screening for thalassaemia during pregnancy: Audit from a national confidential inquiry. BMJ, 320, 337-341.

National Information Forum. (1998). How to provide information well to Bangladeshi, Chinese, Indian, and Pakistani people: A good practice guide. London: Author.

Ottenheimer, M. (1996). Forbidden relatives: The American myth of cousin marriage. Chicago: University of Illinois Press.

Parnes, B. L., \& Westfall, J. M. (2003). An elderly woman with severe anxiety associated with anticipated use of an interpreter. J Am Board Fam Pract, 16, 255-256.

Penchaszadeh, V. B. (2001). Genetic counseling issues in Latinos. Genet Test, 5(3), 193-200.

Phelan, M., \& Parkman, S. (1995). How to work with an interpreter. BMJ, 311, 555-557.

Poss, R. M., Santucci, M. A., \& Mull, C. (1993). Education literature for Hispanic patients. Caring, 12, 104-106.

Roberts, A., Cullen, R., \& Bundey, S. (1996). The representation of ethnic minorities at genetic clinics in Birmingham. J Med Genet, 33, 56-58.

Roberts, C. M. (2001). Meeting the needs of patients with limited English proficiency. J Med Pract Manage, 17, 71-75.

Richards, M., \& Ponder, M. (1996). Lay understanding of genetics: A test of a hypothesis. J Med Genet, 33, 1032-1036.

Sandall, J., Grellier, R., Ahmed, S., \& Savage, W. (2001). Women's access, knowledge and beliefs around prenatal screening in East London. Final report. London: City University, St. Bartholomew School of Nursing and Midwifery.

Schaafsma, E. S., Raynor, T. D., \& de Jong-van den Berg, L. T. (2003). Accessing medication information by ethnic minorities: Barriers and possible solutions. Pharm World Sci, 25, 185-190. 
Sechrest, L., Fay, T. L., \& Hafeez Zaidi, S. M. (1972). Problems of translation in cross-cultural research. J Cross-Cultural Psychol, 3, 41-52.

Shaw, A. (2001). Kinship, cultural preference and immigration: Consanguineous marriage among British Pakistanis. J Roy Anthropol Inst, 7, 315-334.

Shaw, A. (2003a). Genetic counseling for Pakistani and Bangladeshi origin Muslim families in Britain. In The Encyclopedia of the Human Genome (pp. 762-766). Nature Publishing Group, London.

Shaw, A. (2003b). The impact of genetic risk on U.K. Pakistani families. Retrieved from http://www.wellcome.ac.uk/en/genome/geneticsandsociety/hg14f005.html

Shaw, A. (2004). Negotiations of risk among Pakistani-origin users of the genetic services (chap 1). M. Unnithan-Kumar (Ed.), Reproductive agency, medicine and the state: Cultural transformations in childbearing (pp. 25-41). Oxford: Berghahn Books.

Shumaker, S. A., \& Berzon, R. (1995). The international assessment of health-related quality of life: Theory, translation, measurement and analysis. Oxford: Rapid Communications.

Snowdon, C., \& Green, J. M. (1994). New reproductive technologies: Attitudes and experiences of carriers of recessive disorders. Cambridge, UK: University of Cambridge, Centre for Family Research.

Temple, B. (1997). Watch your tongue: Issues in translation and cross-cultural research. Sociology, 31(3), 607-618.

Twinn, S. (1997). An exploratory study examining the influence of translation on the validity and reliability of qualitative data in nursing research. $J$ Adv Nurs, 26, 418-423.

Weil, J. (2001). Multicultural education and genetic counseling. Clin Genet, 59, 143-149.

Woloshin, S., Bickell, N. A., Schwartz, L. M., Gany, F., \& Welch, H. G. (1995). Language barriers in medicine in the United States. JAMA, 273, 724-728.

Xuo, D., \& Fagan, M. J. (1999). Satisfaction with methods of Spanish interpretation in an ambulatory care clinic. J Gen Intern Med, 14, 547-550. 